\title{
Sodium Arsenite Induces Bronchial Epithelial Cell Cancer With Mitochondrial Dysfunction by Affecting Cell Cycle
}

\section{Rong Liu}

Xiamen University School of Public Health

\section{Zifeng Deng}

Xiamen University School of Public Health

Mo Lin

Xiamen University School of Public Health

\section{Fengkai Ruan}

Xiamen University School of Life Sciences

\section{Guangping Luo}

Xiamen University

\section{Zhen Luo}

Xiamen University School of Medicine

\section{Liangding Dou}

Xiamen University School of Public Health

\section{Lei Wang}

Xiamen University School of Public Health

\section{Guihua Qiu}

Xiamen University School of Public Health

\section{Zhi Huang}

Xiamen University School of Public Health

\section{Xin Hou}

Xiamen University School of Public Health

\section{Youliang Yao}

Xiamen University School of Public Health

Yongxing Zhang ( $\nabla$ z63y94x@xmu.edu.cn)

Xiamen University School of Public Health https://orcid.org/0000-0002-0887-9713

\section{Research}

Keywords: Sodium arsenite, Cell cycle, AKAP95, Mitochondrial damage, Lung cancer 
Posted Date: November 8th, 2021

DOl: https://doi.org/10.21203/rs.3.rs-988674/v1

License: (c) (i) This work is licensed under a Creative Commons Attribution 4.0 International License. Read Full License 


\section{Abstract}

Background: Arsenide, a kind of pollution widely existing in the environment, and the mechanism of occurrence and development of lung cancer leading by long-term arsenic exposure still needs further research up to present. We investigated how high and low doses of arsenic induce human bronchial epithelial cell transformation and the molecular mechanisms involved

Methods: After exposing human bronchial epithelial cells(Beas-2B) to different doses of sodium arsenite for $24 \mathrm{~h}$, RNA-seq analysis was performed to detect arsenic-regulated genes; for cell viability and status and for cell cycle changes and mitochondrial function; long-term exposure to $1 \mu \mathrm{M}$ sodium arsenite after 20 consecutive passages for cell cycle changes and mitochondrial function.

Results: In the study, human bronchial epithelial cells were exposed to varying high-dose sodium arsenite in short term or treated with low dose in a long term, and the data showed that both short and long terms treatment promoted G1/S transition of Beas-2B cells, inducing significant increases of expression of AKAP95, cyclin D1, cyclin D2 and cyclin E1. However, silencing AKAP95 by treating cells with siAKAP95 showed a protective function that inhibited G1/S transition, suggesting that regulatory mechanism of AKAP95 on cell cycle during cell malignant transformation induced by sodium arsenite. In addition, we also noticed some mitochondrial dysfunctions occurred during sodium arsenite exposure, including the disappearance of mitochondrial double membrane structure, the formation of vacuole structure, the decrease of mitochondrial membrane potential, the change of expression levels of mitochondrial related proteins Tim22, Tim23, Tom40 and OPA1, the release of lactate dehydrogenase (LDH) and the decrease of reduced glutathione.

Beas-2B cells, which exposed to low-dose sodium arsenite for a long term, were subcultured for 20 generations, and it was found that the exposure time was positively proportional to the growth and migration rate of cells. The exposed cells were used in tumor bearing transplantation experiment (mice), and results showed that the longer the exposure time, the faster the tumor volume growth rate of As-Beas2B cells. Tumor tissues were taken out for HE staining, and it was found that the cell morphology changed and the volume increased

Conclusion: high and low doses of sodium arsenite induced malignant transformation of human bronchial epithelial cells by promoting G1/S turnover through AKAP95 with associated cyclins, accompanied by the development of mitochondrial dysfunction.

\section{Background}

Arsenic and arsenide are common environmental pollution. As naturally deposited quasi metals, they are widely distributed in the natural crust in several oxidation states (3-, 0, 3+ and 5+), organic and inorganic forms[1]. The organic form of arsenic is considered less toxic, because it does not participate in metabolism and accumulate in the human body, while the excretion rate of inorganic forms is slow and it is considered easy to interact with proteins containing sulfhydryl groups in cells, resulting in toxicity. A 
growing number of studies have shown that high-dose in a short term or long-term exposure to arsenic is related to a variety of diseases such as skin, kidney, liver and lung[2-5], and the International Agency for Research on Cancer (IARC) has already classified arsenic as a class I carcinogen[6].

A large number of epidemiological and histopathological studies have showed that exposure to or inhalation of toxic dust in occupational environment (such as mines and chemical plants) is an important route of arsenic exposure, and long-term occupational arsenic exposure is related to the occurrence of lung cancer[7]. Long term exposure makes arsenic accumulate in lung tissue, affecting the occurrence and development of lung cancer. At present, theories supported by related researches on carcinogenic mechanism of arsenic include enhanced oxidative stress response, chromosome aberration, DNA damage and abnormal methylation[8]. However, carcinogenic mechanism of arsenic remains unclear.

A-kinase anchoring protein 95 (AKAP95) is a core member of A-kinase anchoring protein family which is specific to the nucleus and binds to PKA R『[9], and has many functions, such as chromatin concentration, RNA processing et cetera[10]. Our previous study has shown that AKAP95 highly expressed in lung cancer tissues and could bind to cyclins to form complexes, regulating cell cycle process[11]. And there are some studies that point out that arsenic prolong all stages of cell cycle, especially $S$ and $G 2 / M$ phase[12,13]. However, exact relationship between AKAP95 and cell cycle changes in arsenic carcinogenesis has not been proved so far.

As the core component of cell energy conversion and metabolism, the abnormal morphology and function of mitochondria are related to cell proliferation, malignant transformation and death, and mitochondrial dysfunction caused by high levels of mitochondrial ROS is currently recognized as a marker of tumorigenesis[14]. Even though it has been proved that mitochondria are the main target organ of cytotoxicity induced by monomethylarsenate (MMA), there is a lack of study on mitochondrial dysfunction in arsenic induced malignant transformation of human bronchial epithelial cells at present. We further discussed the topic in the study.

In general, we aimed at determining the potential mechanism of AKAP95 in arsenic induced carcinogenesis of human bronchial epithelial cells and the role of mitochondrial dependent pathway in carcinogenesis.

\section{Methods And Materials}

\subsection{Animal and tumor bearing experiments}

All female BALB/C nude mice were purchased from the animal experiment center of Xiamen University (Xiamen, China) and used based on the regulations of the Animal Care and Use Committee (IACUC) and approved by the ethics committee of Xiamen University. 
$5 \times 10^{6}$ Beas-2B cells, which were continuously exposed to $1 \mu \mathrm{M} / \mathrm{L}$ sodium arsenite $\left(\mathrm{NaAsO}_{2}\right)$ for three months, were mixed with Matrigel and then injected subcutaneously into the left hindlimb of nude mice. Twenty-four female BALB/C nude mice aged 6-8 weeks were randomly divided into six groups, including negative control, mice bearing fifth generation cells, mice bearing tenth generation cells, mice bearing fifteenth generation cells, mice bearing twentieth generation cells and positive control group. The weight of nude mice was monitored the next day after injection and the tumor bearing volume was measured with vernier caliper. The nude mice were killed by cervical dislocation and the tumor bearing tissues were removed after 24 days of cell injection, and half of the tissues were fixed in $4 \%$ paraformaldehyde for histological analysis and half were frozen in liquid nitrogen and stored in a refrigerator at $-80^{\circ} \mathrm{C}$.

\section{2 cell culture}

Human bronchial epithelial cells (BEAS-2B) and lung adenocarcinoma epithelial cells (A549) were obtained from the cell bank of the typical culture preservation center of the Chinese Academy of Sciences, and the cells were cultured in DMEM medium containing $10 \%$ fetal bovine serum and double chain antibiotics ( $100 \mathrm{IU} /$ penicillin and $100 \mu \mathrm{G} / \mathrm{mL}$ streptomycin) at $37^{\circ} \mathrm{C}$ and $5 \% \mathrm{CO}_{2} . \mathrm{NaAsO}_{2}(\mathrm{CAS}$ : 7784-46-5) was obtained from sigma Aldrich. Accurately weigh $11.7 \mathrm{mg}$ of $\mathrm{NaAsO}_{2}$ and dissolve it in $45 \mathrm{~mL}$ ultrapure water after high-pressure sterilization, then filter it with $0.22 \mathrm{~nm}$ filter membrane to make its final concentration $2 \mathrm{~mm} / \mathrm{L}$, and store it away from light at $-20^{\circ} \mathrm{C}$. Beas-2B cells were exposed to $1 \mu \mathrm{M}$ $\mathrm{NaAsO}_{2}$ and sub cultured for every 3-4 days, continuous passage for 20 generations; or treated with 0,2 , 4, 8, $10 \mu \mathrm{M} \mathrm{NaAsO}{ }_{2}$ for 24 hours.

\subsection{Cell viability assay}

The viability changes of Beas-2B cells induced by $\mathrm{NaAsO}_{2}$ were measured according to the instructions of CCK-8 detection kit (CA1210-500t, Solarbio, China). Cells were plated in 96 hole $\left(1 \times 10^{4}\right.$ cells/well) and exposed to $0,1,2,4,8$ and $10 \mu \mathrm{M} \mathrm{NaAsO}{ }_{2}$ respectively for 24 hours, then $10 \mu \mathrm{L}$ CCK-8 solution was added to each hole and the plate was incubated in the dark at $37^{\circ} \mathrm{C}$ for 1 hour. The absorbance at $450 \mathrm{~nm}$ wavelength was measured with a spectrophotometer (thermo, USA).

\subsection{Cell cycle detection}

The cell suspension ( $5 \times 10^{5}$ per well) was incubated in $0,2,4,8$ and $10 \mu \mathrm{M} \mathrm{NaAsO}{ }_{2}$ respectively in the plate (six hole) and cells were collected after 24 hours of the treatment. The cells were washed three times with precooled phosphate buffer (PBS) and fixed with $75 \%$ ethanol at $4{ }^{\circ} \mathrm{C}$ overnight. PI staining was used to incubate collected cells at $37^{\circ} \mathrm{C}$ for 30 minutes and cell cycle was detected by flow cytometry (BD Biosciences, USA).

\subsection{Determination of GSH and LDH}

According to the instructions, the contents of GSH and LDH in cells are detected by the detection kit (BC1175\&BC0685, Solarbio, China).

\subsection{Measurement of mitochondrial membrane potential}


Mitochondrial membrane potential was detected by JC-1 fluorescent probe (M8650, Solarbio, China). The cell suspension ( $5 \times 10^{5}$ per well) was incubated in $0,2,4,8$ and $10 \mu \mathrm{M} \mathrm{NaAsO} \mathrm{N}_{2}$ respectively in the plate (six hole) and cells were collected after 24 hours of the treatment. Collected cells were stained with JC-1 for 20 minutes and detected by flow cytometry (BD Biosciences, USA) after washing by $1 \mathrm{x} \mathrm{JC}-1$ dyeing buffer twice.

\subsection{SiRNA transient transfection}

AKAP95 siRNA (Hanheng Biology, Shanghai, China) was transfected into Beas-2B cells by UltraFection3.0 for 48 hours and exposed to $4 \mu \mathrm{M} \mathrm{NaAsO}{ }_{2}$ for 24 hours, and cells were collected then. Sequences of siAKAP95 were: Justice chain: 5'-GUUUGGACAUGAUGUCCAA-3'; Antisense chain: 5'UUGGACAUCAUGUCCAAAC-3'.

\subsection{Transmission electron microscope (TEM)}

Transmission electron microscope was used to observe mitochondria of cells treated with $\mathrm{NaAsO}_{2}$. Beas2B cells were exposed to $4 \mu \mathrm{M} \mathrm{NaAsO}{ }_{2}$ and collected after 24 hours, then washed by precooled $1 \times \mathrm{PBS}$ and fixed at $4{ }^{\circ} \mathrm{C}$ in $2.5 \%$ glutaraldehyde solution overnight. Fix exposed cells at $1.5 \%$ hydrogen tetroxide for 1 hour before dehydrate the cells with different concentrations of ethanol under concentration gradient. Then the precipitation was embedded in the resin, stained with lead citrate and uranyl acetate, and observed and analyzed by TEM (FEI TECNAI spirit, Holland).

\subsection{Western blot (WB)}

RIPA (Radio Immunoprecipitation Assay, P0013B, Beyotime, China) lysate, containing 1 mM Phenylmethylsulfonyl fluoride (PMSF, ST50, Beyotime, China), was used to lyse cells and tumor tissues and extract total proteins. BCA detection kit was used to perform protein quantification. The total protein was separated by SDS-PAGE and transferred to the PVDF membrane by wet electrophoretic transfer after denaturation. The membrane was sealed with $8 \%$ skimmed milk powder for 1 hour at room temperature and incubated with the primary antibody at $4{ }^{\circ} \mathrm{C}$ overnight. After incubated at room temperature for 2 hours in the secondary antibody coupled with peroxidase then, ECL kit and Bio-Rad ChemiDoc XRS imaging system were used to detect protein expression level and data was analyzed by Image $\mathrm{J}$ software.

\subsection{Real time quantitative polymerase chain reaction(qRT- PCR)}

Total RNA was isolated from the collected cells using Trizol total RNA Extraction Kit (R0016, Beyotime, China) and first strand cDNA was synthetic by reverse transcriptase. The primer sequence and SYBR Premix Ex Taq TM (AG11701, Accurate Biotechnology, Hunan, China) were used to analyze the relative expression level of genes, and GAPDH was detected as the reference gene.

\subsection{RNA-seq}


Total RNA of Beas-2B cells was extracted with Trizol after the 24-hour treatment in $4 \mu \mathrm{M} \mathrm{NaAsO}{ }_{2}$. HiSeq $\times 10$ system (Illumina, Inc.) was used for computer sequencing and differentially expressed genes (DEG) were determined by $\mid \log _{2}$ FoldChange $\mid>1$ and $P a d j<0.05$.

\subsection{Statistical analysis}

Data showed in the article were analyzed by SPSS21.0 and expressed as the mean \pm standard deviation of three independent experiments if there were no additional instructions in specific paragraphs. Non parametric t-test was used for analysis and comparison and $p<0.05$ was considered to be statistically significant.

\section{Results}

\section{1 $\mathrm{NaAsO}_{2}$ induced viability changes of human bronchial epithelial cells.}

Cell viability was analyzed by CCK-8 kit after Beas-2B cells were treated with $\mathrm{NaAsO}_{2}(0,1,2,4,8,10 \mu \mathrm{M})$ for 24 hours, and our results showed that $1 \mu \mathrm{M} \mathrm{NaAsO} \mathrm{N}_{2}$ promoted the viability of Beas-2B cells, while highdose exposure induced a decrease of cell viability in a dose-dependent manner (Fig. 1A) and the cell morphology gradually changed from spindle to round (Fig. 1B), compared to the Control. When the concentration of $\mathrm{NaAsO}_{2}$ was controlled at $4 \mu \mathrm{M}$, the cell viability decreased to $70 \%$ of the control group; and when the concentration increased to $10 \mu \mathrm{M}$, the cell viability was only $42 \%$ of that of the control group, indicating that a low dose $(1 \mu \mathrm{M}) \mathrm{NaAsO}_{2}$ treatment promoted the proliferation, while high dose (2 $\mu \mathrm{M}) \mathrm{NaAsO}_{2}$ could induce a dose-dependent viability decrease and change the cell morphology in Beas2B cells.

\subsection{Genome-wide expression differences of mRNA in Beas- 2B cells induced by $\mathrm{NaAsO}_{2}$ detected by RNA-seq assay.}

By RNA-seq assay, we detected the genome-wide mRNA changes induced by $\mathrm{NaAsO}_{2}$ and analyzed the changes of genes or pathways related to cell cycle and mitochondrial damage of Beas-2B cells. Based on the cell viability results, cells were treated with $4 \mu \mathrm{M} \mathrm{NaAsO}_{2}$ for 24 hours and then collected for RNA-seq sequencing. The differential gene (DEG) was determined by $\mid \log _{2}$ FoldChangel $>1$ and Padj $<0.05$ and results were shown in Figure.2.

Box diagram of gene expression level distribution of As-Beas-2B and Beas-2B cells was displayed in Fig. $2 A$, showing that the distribution of $\log _{10}$ (Fragments Per Kilo base of exon model per Million mapped fragments $+1, F P K M+1$ ) between $A s-B e a s-2 B$ and Beas-2B was similar, indicating that the standardized gene expression data could truly reflect the biological differences of samples. Hierarchical 
cluster analysis could cluster samples with similar expression patterns and showed the expression of the same gene among different samples, and as Fig. 2B showed, the three duplicate samples of the same treatment were gathered together, suggesting that the biological repeatability of the sample was qualified. Fig. $2 \mathrm{C}$ showed the volcanic diagram of co-expressed genes between As-Beas-2B and Beas-2B cells: there were a total of 1699 differential genes between the two groups, of which.855 genes were up-regulated while 844 genes were down regulated.

The DEGs were analyzed by gene ontology (GO) function enrichment analysis and KEGG pathway analysis. Results of GO function enrichment analysis showed main enrichment items of up and down regulation,and enrichment items of up regulation mainly included pathway of targeting endoplasmic reticulum protein, pathway of apoptosis signal transduction, release of mitochondrial cytochrome $\mathrm{C}$ and activity of growth factor (Fig. 3A); items of down regulation mainly included ATP activity, cell adhesion factor, cell growth and cell migration et central (Fig. 3B).

A total of 244 up and 273 down-regulated pathways were enriched in KEGG annotation information, of which the up-regulated pathways in Figure 3 were most enriched in seven pathways, including glycine threonine metabolism, iron death and transcriptional imbalance in cancer et central (Figure 3C); and down-regulated pathways were enriched in small cell lung cancer, cell cycle and response of ECM receptor, et central (Fig. 3D).

\section{3 $\mathrm{NaAsO}_{2}$ induced changes of $\mathrm{G} 1 / \mathrm{S}$ transition.}

To further verify the difference of expression of genes relating to G1/S transition in RNA-seq results of Beas-2B cells treated with $\mathrm{NaAsO}_{2}$, we used real-time quantitative polymerase chain reaction (qRT-RCR) to verify the expression of some differential genes (Fig. $4 \mathrm{~A})$. Our data of exposed cells $\left(1 \mu \mathrm{M} \mathrm{NaAsO} \mathrm{N}_{2}\right.$ treatment for 24h) showed that the gene expression levels of cyclin D1, cyclin D2, cyclin E1, cyclin dependent kinase 2 (CDK2) and cyclin dependent kinase inhibitors p15 and p21 increased significantly (Fig. 4B), while the mRNA levels of cyclin dependent kinase 4/6 (CDK4/6) and cyclin dependent kinase inhibitors p16 and p27 decreased slightly. And we also found that there was a decrease of gene expression level of ubiquitin ligase E3, like F-box and WD repeat containing protein 8 (FBXW8) and F-box only protein 4 (FBXO4) that mediated ubiquitination of cyclin D1, F-box and Leucine-rich repeat protein 2 (FBXL2) that mediated ubiquitination of cyclin D2 and F-box and WD repeat containing protein 7 (FBXW7) that mediated ubiquitination of cyclin E1, while gene expression of F-box only protein 31 (FBX031) that mediated ubiquitination of cyclin D1 was up-regulated under the treatment. In addition, our previous studies had shown that AKAP95 promoted cell cycle by increasing expression of cyclin Ds/Es, and, here, our RNA-seq results also showed that the expression level of AKAP95 gene was increased (about doubled).

After 24 hours exposure to $\mathrm{NaAsO}_{2}$ with different concentrations, expression levels of AKAP95 and cyclin Ds/Es were detected by WB assay, and results showed that, compared with the control group, expression levels of AKAP95, cyclin D1, cyclin D2 and cyclin E1 were significantly up-regulated when cells were 
exposed to $2 \mu \mathrm{M} \mathrm{NaAsO}_{2}$ (Fig. 4C, 4D). With the dose increase of $\mathrm{NaAsO}_{2}$, expression of each protein mentioned above showed an obvious upward trend and a dose-dependent relationship. Meanwhile, changes of cell cycle of exposed Beas-2B under treatments with different doses of $\mathrm{NaAsO}_{2}$ were measured by flow cytometry, and the results were shown in Figure 4E. Compared with the control group, the proportion of cells at $\mathrm{G} 1$ phase and $\mathrm{G} 2$ phase treated with different doses all decreased with the dose increase of $\mathrm{NaAsO}_{2}$, while the proportion of $\mathrm{S}$ phase increased under the same situation.

To further discuss influence of AKAP95 on cell cycle under $\mathrm{NaAsO}_{2}$ treatment, we silenced AKAP95 by transfecting siAKAP95 and analyzed how interaction between AKAP95 and $\mathrm{NaAsO}_{2}$ influenced protein expressions of cyclin D1, cyclin D2 and cyclin E1. Results were displayed in Fig. 4F: compared with the control group (WT cells) in the first column, bands of the second column showed that the expression of AKAP95, cyclin D1, cyclin D2 and cyclin E1 in WT cells treated with $\mathrm{NaAsO}_{2}$ was higher; bands of the third column showed that the expression of cyclin E1 in AKAP95 silenced WT cells decreased and no significant changes of expressions of cyclin D1 and cyclin D2 were observed; bands of the forth column showed expression levels of AKAP95, cyclin D1, cyclin D2 and cyclin E1 recovered and increased compared to those in the third column. These data indicated that, when AKAP95 and $\mathrm{NaAsO}_{2}$ both existed in cells (column 2), expressions of AKAP95, cyclin D1, cyclin D2 and cyclin E1 all peaked, while their expressions were the lowest among all groups when none of them existed (column 3 ). The statistical results of their interaction were displayed in Figure $G$, which showed an additive role in promoting the expression levels of cyclin D1, cyclin D2 and cyclin E1 played AKAP95 and $\mathrm{NaAsO}_{2}$. In addition, by detecting cell cycle of treated cells under the interaction of AKAP95 and $\mathrm{NaAsO}_{2}$, we found that $\mathrm{NaAsO}_{2}$ treatment decreased the proportion of $\mathrm{G} 0 / \mathrm{G} 1$ phase cells and increased the proportion of $\mathrm{S}$ phase cells, while siAKAP95 treatment significantly decreased the proportion of $S$ phase cells and increased the proportion of $\mathrm{G} 2$ phase cells (Figure $4 \mathrm{H}$ ).

\subsection{Long term exposure to low dose $\mathrm{NaAsO}_{2}$ induced carcinogenesis of human bronchial epithelial cells.}

Beas-2B cells were continuously cultured in a medium containing $1 \mu \mathrm{M} \mathrm{NaAsO}{ }_{2}$ for 20 generations (about 3 months), and detected whether the proliferation and migration rate of cells changed. Our results in Fig. $5 \mathrm{~A}$ showed that, $48 \mathrm{~h}$ after the scratching on the plate, the more cell generations, the farther the healing distance of cell scratch, suggesting that the proliferation rate of As-Beas-2B cells was accelerated and the migration ability was strengthened. And the cell cycle of $0,5,10,15$ and 20 generations As-Beas2B cells was detected by flow cytometry, and results were displayed in Fig. 5B, showing that the more the cell generation, the lower the proportion of $\mathrm{G} 1$ while the higher the proportion of $\mathrm{S}$ phase cells.

As-Beas-2B cells at different stages were inoculated subcutaneously into the left hindlimb of mice, and the growth of volume of tumor tissue was monitored for 24 days. Compared with normal Beas-2B cell groups, no significant changes of volume of bear tumor tissue in the 5th generation As-Beas-2B cells group was detected; volume of tumor tissue grew significantly in 16 days after the injection, in in the 10th 
and 15th generation As-Beas-2B cells groups; volume of tumor tissue of the 20th generation As-Beas-2B group was similar to that of A549 group, and the growth rate of volume of tumor tissue increased significantly from the 10th day after injection and significantly higher than that of A549 group. The tumor was removed from mice on the 24th day after injection, then photographed and measured (Fig. 5D, 5E). Some tissues were taken for $\mathrm{HE}$ staining to further verify that continuous low-dose $\mathrm{NaAsO}_{2}$ exposure induced the canceration of Beas-2B cells. As shown in Fig. 5F, after low-dose $\mathrm{NaAsO}_{2}$ exposure, the cell morphology of tumor tissue changed with different cell sizes, significantly increased nucleus and widened cell gap, from 5th generation.

In order to further investigate whether continuous low-dose $\mathrm{NaAsO}_{2}$ exposure induced cell cycle changes, we then detected expressions of some cell cycle related proteins in tumor tissues, and our data showed that the expression of AKAP95, cyclin D1, cyclin D2 and cyclin E1 were all up-regulated (Fig. 5G).

In general, our results suggested that continuous low-dose $\mathrm{NaAsO}_{2}$ exposure could promote the cell growth and migration, accelerate cell cycle transition, and induce cell carcinogenesis.

\section{5 $\mathrm{NaAsO}_{2}$ exposure triggered mitochondrial damage.}

Our early Go function enrichment and KEGG pathway analysis results of RNA-seq enriched mitochondrial cytochrome $C$ release, ATP activity, ECM receptor response etc. pathways related to mitochondrial function, suggesting that $\mathrm{NaAsO}_{2}$ exposure might induce changes in mitochondrial structure and function. RNA-seq results of Beas-2B cells treated with $4 \mu \mathrm{M} \mathrm{NaAsO}_{2} 24$ hours showed that the mRNA expression levels of mitochondrial damage related genes Tim 22, Tim 23 and Tom 40 increased (Fig. 6A), while mRNA expression level of OPA1, which mediates mitochondrial fusion, was down regulated. After verification, results of RNA-seq and qRT-PCR were consistent (Fig. 6B).

By TEM assay, we detected the cells exposed in $4 \mu \mathrm{M} \mathrm{NaAsO}_{2}$ for $24 \mathrm{~h}$ and found that the volume of mitochondria in cells increased significantly, compared with untreated cells, and the dual-mode structure of both inner and outer membrane disappeared into a single membrane structure and the mitochondrial ridge shrank into fragments (Fig. $6 \mathrm{C}$ ). And by detecting the expression of mitochondrial outer membrane channel forming protein Tom 40, mitochondrial inner membrane carrier protein Tim 22, mitochondrial inner membrane leading sequence transposase Tim 23 and mitochondrial fusion protein OPA1, we found that after Beas-2B cells were treated with different concentrations $(0,2,4,8,10 \mu \mathrm{M}) \mathrm{NaAsO}_{2}$ for 24 hours, the protein expression levels of Tim 22 and Tim 23 decreased significantly with the increase of $\mathrm{NaAsO}_{2}$ concentration, showing a significant dose-dependent manner; when the concentration reaches $10 \mu \mathrm{M}$, the expression of Tim 22 and Tim 23 decreased to 0.5 and 0.33 times that of the control group, suggesting that $\mathrm{NaAsO}_{2}$ could significantly reduce the expression of Tim22 and Tim 23, and, in addition, expression of OPA1 also showed a gentle downward trend when concentration of $\mathrm{NaAsO}_{2}$ was $0,2,4$ or $8 \mu \mathrm{M}$ and significantly decreased when the concentration was $10 \mu \mathrm{M}$; however, Tom40 showed an obvious upward trend with the increase of $\mathrm{NaAsO}_{2}$ concentration and also showed a significant dose-dependent manner (Fig. 6D). 
To investigate whether continuous low-dose $\mathrm{NaAsO}_{2}$ exposure could induce mitochondrial dysfunction, we detected expressions of mitochondrial damage associated proteins in bare tumor tissues (different generations cells exposed continuously to $1 \mu \mathrm{M} \mathrm{NaAsO}{ }_{2}$ ), and results showed that expressions of Tim22, Tim23 and OPA1 decreased significantly from the 15th generation cells' group, while that of Tom40 increased (Fig. 6E), suggesting that continuous low-dose $\mathrm{NaAsO}_{2}$ exposure induced cell carcinogenesis, and accompanied by mitochondrial dysfunction.

Mitochondrial membrane potential is considered as an important index to indicate changes of membrane permeability. In our study, the mitochondrial membrane potential of Beas-2B cells decreased significantly after $\mathrm{NaAsO}_{2}$ treatment, and cell proportion in Q3 increased (Fig. 7A). Reduced glutathione (GSH), as an important antioxidant in cells, can cause the accumulation of oxygen free radicals and induce oxidative stress. And after $\mathrm{NaAsO}_{2}$ exposure, we found that $\mathrm{GSH}$ levels were effectively reduced in cells, as shown in Fig. 7B. LDH release is regarded as an important indicator of cell membrane integrity, and in $\mathrm{NaAsO}_{2}$ treated cells, the LDH level in the culture supernatant of BEAS-2B cells decreased, in a dose-dependent manner (Fig. 7C), suggesting that the damage of $\mathrm{NaAsO}_{2}$ to cell membrane permeability increased gradually with the increase of $\mathrm{NaAsO}_{2}$ dose. All these results indicated that effects of $\mathrm{NaAsO}_{2}$ on BEAS2B cells induces changes in mitochondrial structure and functions.

\section{Discussion}

Arsenic is worldwide considered as a dangerous substance threatening human health, and its toxic effect on the body is much higher than our current cognition. Arsenic exposure is associated with multiple organ lesions, including lung, bladder and skin, and extensive previous studies have confirmed that short-term and high-dose arsenic exposure could induce cell cycle changes, including changes of G1/S transition and G2 phase (Cell lines and experimental conditions errors might lead to different results). However, the molecular mechanisms affecting cell cycle changes, induced by $\mathrm{NaAsO}_{2}$ remains unclear so far. In addition, mitochondrial dysfunction is currently recognized as a marker of cancer[15], and it is essential to clarify the role of arsenic triggered mitochondrial damage in arsenic induced malignant transformation of human bronchial epithelial cells. In the study, we had exposed cells to short-term arsenic and long-term low-dose $\mathrm{NaAsO}_{2}$ exposure, and our data showed that $\mathrm{NaAsO}_{2}$ might induce $\mathrm{G} 1 / \mathrm{S}$ phase changes by affecting expression of AKAP95 and related cyclins, and triggered mitochondrial damage and cell carcinogenesis.

There are three important checkpoints in the cell cycle, controlling the transformation of G1/S, G2/M and transition of metaphase and anaphase respectively[16]. Normal regulation of transition point and expression of related proteins regulate the cell cycle orderly, and the imbalance of these checkpoints usually promote the occurrence of cancers $[17,18]$. Our Go function analysis of RNA-seq results showed that sodium arsenide had an effect on the G1/S checkpoint transition of Beas-2B cells, and flow cytometry analysis of Beas-2B cells exposed to $\mathrm{NaAsO}_{2}$ showed that the proportion of cells in $\mathrm{G} 1$ phase decreased and that of $\mathrm{S}$ phase increased significantly, suggesting that $\mathrm{NaAsO}_{2}$ promoted the $\mathrm{G} 1 / \mathrm{S}$ 
transition. Therefore, based on these data, the regulation mechanism of cycle transition was further discussed.

Existing immune histochemical results of our laboratory[19-21] showed that the expression of AKAP95, cyclin D1, cyclin D2 and cyclin E1 in cancer tissues was higher than that in adjacent tissues, and expression of above proteins was correlated. CCNDs and CCNEs are considered as proto-oncogenes, and cyclin Ds and cyclin Es are mainly synthesized and play a role in $\mathrm{G} 1$ phase[22, 23]. Dumond JW Jr et al. [24] pointed out that long-term low concentration exposure to arsenic could increase the expression of CCND1 in TM3 cells. And according to our data, results of RNA-seq and qRT-PCR both showed that after short-term exposure to $4 \mu \mathrm{M} \mathrm{NaAsO}_{2}$, gene and protein expression levels of AKAP95, cyclin D1, cyclin D2 and cyclin E1 all increased, while RNA-seq results showed that the expression levels of gene mediating ubiquitination and degradation of cyclin D1/D2 and cyclin E1 were reduced. Previous studies had shown that the ubiquitination and degradation of cyclins depend on cell cycle changes, and the carcinogenic function of cyclins depend on their nuclear accumulation in S phase, therefore we suspected that the accumulation of cell cycle related genes and proteins induced by $\mathrm{NaAsO}_{2}$ might be related to the decrease of expression levels of related ubiquitin ligase E3[25], and then promoted the G1/S transition and induced malignant transformation of bronchial epithelial cells. Cell cycle dependent kinases (CDKs) and cell late dependent kinase inhibitors (CKIs) play important roles in the cell cycle regulatory network, and it is known that p15 and p16 specifically inhibit the phosphorylated kinase activity of cyclind-cdk4/6 complex, and p21 and p27 specifically inhibit the function of cyclin E/A-CDK2 complex. Our study showed that, after short-term exposure to $4 \mu \mathrm{M} \mathrm{NaAsO}_{2}$, the mRNA levels of p16, p21 and CDK2 were increased, while the mRNA levels of p15, p27, CDK4 and Cdk6 decreased, suggesting that the mechanisms of the four kinases controlling the cell cycle by regulating activities of CDKs and CDKscyclin complexes were different.

And our highlight was, human bronchial epithelial cells exposed to low-dose sodium arsenite for 3 months and tumor bearing experiments were carried out, and our results revealed that $\mathrm{NaAsO}_{2}$ could indeed induce carcinogenesis of Beas-2B cells, further confirming the molecular mechanism of carcinogenesis in long-term arsenic exposure environment.

Mitochondria, the main place of aerobic respiration, are the main organelles to meet the energy needs of cells. Its various metabolic processes are the key to maintain the normal states and functions of cells[26]. Proteins existing on the outer membrane of mitochondria participate in processes like material transmembrane transport, and Tom40, as the only channel forming protein of TOM complex[27], plays an important role in transporting precursor proteins into mitochondria. The inner membrane of mitochondria folds inward to form mitochondrial ridge and increase the inner membrane area. Tim20, Tim22, Tim23, OPA1etc. distributed in the inner membrane of mitochondria are mainly involved in the following biological processes: Protein transport mediated by Intimal transporter (Tim), oxidative phosphorylation, ATP synthesis and mitochondrial fusion mediated by OPA1. OPA1 plays an important role in the maintenance and change of cristae morphology. The lack of OPA1 will cause the change of mitochondrial membrane potential and the decrease and morphological change of mitochondrial cristae. 
After short-term high-dose arsenic exposure to Beas-2B cells, we found that arsenic caused mitochondria to swell into vacuoles, double membrane structure disappeared, and mitochondrial cristae melt into fragments, under transmission electron microscope. It was also found that arsenic caused the loss of mitochondrial membrane potential, which would lead to the depolarization and permeability of mitochondrial membrane. Once the permeability of mitochondrial membrane changed, the outer mitochondrial membrane would release apoptosis factor and mitochondrial cytochrome $c$ to the interior of mitochondria. In addition, we demonstrated that the concentrations of GSH and LDH decreased in cells exposed to sodium arsenide, indicating that the antioxidant capacity of mitochondria was destroyed and oxidative damage occurred. Our results of transcriptome analysis also supported the above results and showed that $\mathrm{NaAsO}_{2}$ exposure affected ATP metabolism, cytochrome c release, mitochondrial membrane permeability and so on.

As one of the target organs exposed to sodium arsenide[28], the structure and function changes of mitochondria will reduce the efficiency of energy metabolism, and then lead to the malignant transformation of cells. And in our study, high or low dose $\mathrm{NaAsO}_{2}$ exposure could induce changes in mitochondrial related proteins, and the reasons might be: 1 . The mild mitochondrial damage caused by low-dose sodium arsenide exposure could be repaired by the cell itself, to ensure the production of energy and the synthesis of required protein, so it did not affect the cell survival. 2. High dose $\mathrm{NaAsO}_{2}$ exposure would induce drastic changes in mitochondrial membrane permeability, seriously affected the oxidative respiratory chain, and lead to mitochondrial dysfunction and even cell death.

\section{Conclusions}

In conclusion, our study on short-term high-dose and long-term low-dose sodium arsenide exposure of cells suggested that arsenic might induce carcinogenesis of human bronchial epithelial cells by promoting G1/S turnover through AKAP95 with associated cyclins, accompanied by the development of mitochondrial dysfunction.

\section{Abbreviations}

IRAC: International Agency for Research on Cancer

AKAP95: A-kinase anchoring protein 95

PKA R囚: Protein Kinase A R

MMA: Monomethylarsenate

Beas-2B: Human bronchial epithelial cells

$\mathrm{NaAsO}_{2}$ : Sodium arsenite 
As-Beas-2B: Sodium arsenite-treated cells

A549: Human lung adenocarcinoma cells

DMEM: Dulbecco minimal essential medium

CCK-8: Cell Counting Kit-8

GSH: L-Glutathione

LDH: Lactate dehydrogenase

siRNA: Small interfering RNA

TEM: Transmission electron microscope

WB: Western blot

qRT-PCR: Real-time quantitative polymerase chain reaction

RNA-seq: RNA Sequencing

DEG: Differentially expressed genes

GO: Gene Ontology

KEGG: Kyoto Encyclopedia of Genes and Genomes)

Cyclin Ds/Es: Cell cycle protein Ds/Es

CDKs: Cyclin dependent kinases

\section{Declarations}

\section{Ethics approval and consent to participate}

All animal experiments were conducted according to the protocol approved by the Animal Care and Use Committee of the Xiamen University (protocol no. XMULAC20170332).

\section{Consent for publication}

All the authors read and approved the final version of the manuscript to be published.

\section{Availability of data and material}


The datasets generated and/or analysed during the current study are not publicly available due [Reason why data are not public] but are available from the corresponding author on reasonable request.

\section{Competing interests}

The authors declare that they have no conflicts of interest.

\section{Funding}

This study was supported by the National Natural Science Foundation of China (NSFC 81971905).

\section{Contributions}

YX.Z, R.L and FK.R designed the experiments and revised the manuscript. R.L performed the main experiments and wrote the manuscript. ZF.D, M.L, FK.R, and GP.L gathered and analyzed the raw data. Z.L, LD.D, L.W, GH.Q, Z.H and X.H performed the experiments.YX.Z and YL.Y Administrative, technical, or material support. All authors read and approved the final manuscript.

\section{Acknowledgments}

Not applicable.

\section{References}

1. Rodríguez-Lado, L., et al., Groundwater Arsenic Contamination Throughout China. Science, 2013. 341(6148): p. 866-868.

2. Guo, X., et al., Multi-generational impacts of arsenic exposure on genome-wide DNA methylation and the implications for arsenic-induced skin lesions. Environ Int, 2018. 119: p. 250-263.

3. Wei, W., et al., Arsenic exposure and its joint effects with cigarette smoking and physical exercise on lung function impairment: Evidence from an occupational cohort study. Environ Res, 2021. 196: p. 110419.

4. Chang, Y.W. and K.P. Singh, Arsenic induces fibrogenic changes in human kidney epithelial cells potentially through epigenetic alterations in DNA methylation. J Cell Physiol, 2019. 234(4): p. 47134725 .

5. Islam, K., et al., Dose-response relationship between arsenic exposure and the serum enzymes for liver function tests in the individuals exposed to arsenic: a cross sectional study in Bangladesh. Environmental health : a global access science source, 2011. 10: p. 64-64. 
6. Humans, I.W.G.o.t.E.o.C.R.t., Arsenic, metals, fibres, and dusts. Monogr Eval Carcinog Risks Hum, 2012. 100(Pt C): p. 11-465.

7. Overall evaluations of carcinogenicity: an updating of IARC Monographs volumes 1 to 42 . IARC Monogr Eval Carcinog Risks Hum Suppl, 1987. 7: p. 1-440.

8. Dong JJ, X.H., Research progress on lung cancer caused by arsenic. Journal of Environmental Hygiene, 2015. 2015,5(05): p. 483-486+489.

9. Clister, T., et al., AKAP95 Organizes a Nuclear Microdomain to Control Local cAMP for Regulating Nuclear PKA. Cell Chem Biol, 2019. 26(6): p. 885-891.e4.

10. Li, W., et al., Biophysical properties of AKAP95 protein condensates regulate splicing and tumorigenesis. Nat Cell Biol, 2020. 22(8): p. 960-972.

11. Kong, X.Y., et al., AKAP95 promotes cell cycle progression via interactions with cyclin E and low molecular weight cyclin E. Am J Transl Res, 2016. 8(2): p. 811-26.

12. Lehmann, G.M. and M.J. McCabe, Jr., Arsenite slows $S$ phase progression via inhibition of cdc25A dual specificity phosphatase gene transcription. Toxicol Sci, 2007. 99(1): p. 70-8.

13. McCollum, G., et al., Arsenite delays progression through each cell cycle phase and induces apoptosis following G2/M arrest in U937 myeloid leukemia cells. J Pharmacol Exp Ther, 2005. 313(2): p. 877-87.

14. Roth, K.G., et al., The Mitochondrion as an Emerging Therapeutic Target in Cancer. Trends Mol Med, 2020. 26(1): p. 119-134.

15. Luo, Y., J. Ma, and W. Lu, The Significance of Mitochondrial Dysfunction in Cancer. International Journal of Molecular Sciences, 2020. 21(16): p. 5598.

16. Matthews, H.K., C. Bertoli, and R.A.M. de Bruin, Cell cycle control in cancer. Nat Rev Mol Cell Biol, 2021.

17. Visconti, R., R. Della Monica, and D. Grieco, Cell cycle checkpoint in cancer: a therapeutically targetable double-edged sword. J Exp Clin Cancer Res, 2016. 35(1): p. 153.

18. Ganapathy, S., et al., Chronic low dose arsenic exposure preferentially perturbs mitotic phase of the cell cycle. Genes Cancer, 2019. 10(1-2): p. 39-51.

19. Hu, S.X., et al., [Relationship between AKAP95, cyclin E1, cyclin D1, and clinicopathological parameters in lung cancer tissue]. Zhonghua Lao Dong Wei Sheng Zhi Ye Bing Za Zhi, 2013. 31(12): p. 890-4.

20. Wang, S., et al., Correlation between the protein expression levels of A-kinase anchor protein95, pretinoblastoma (Ser780), cyclin D2/3, and cyclin E2 in esophageal cancer tissues. Asia Pac J Clin Oncol, 2019. 15(5): p. e162-e166.

21. Huang, P., et al., Epac1, PDE4, and PKC protein expression and their association with AKAP95, Cx43, and cyclinD2/E1 in breast cancer tissues. Thorac Cancer, 2017. 8(5): p. 495-500.

22. Gao, X., G.W. Leone, and H. Wang, Cyclin D-CDK4/6 functions in cancer. Adv Cancer Res, 2020. 148: p. 147-169. 
23. Caruso, J.A., et al., Low-Molecular-Weight Cyclin E in Human Cancer: Cellular Consequences and Opportunities for Targeted Therapies. Cancer Res, 2018. 78(19): p. 5481-5491.

24. DuMond, J.W., Jr. and K.P. Singh, Gene expression changes and induction of cell proliferation by chronic exposure to arsenic of mouse testicular Leydig cells. J Toxicol Environ Health A, 2007. 70(13): p. 1150-4.

25. Gladden, A.B., et al., Expression of constitutively nuclear cyclin D1 in murine lymphocytes induces Bcell lymphoma. Oncogene, 2006. 25(7): p. 998-1007.

26. Chiang, C.J. and Y.H. Hong, In situ delivery of biobutyrate by probiotic Escherichia coli for cancer therapy. Sci Rep, 2021. 11(1): p. 18172.

27. Kang, Y., L.F. Fielden, and D. Stojanovski, Mitochondrial protein transport in health and disease. Semin Cell Dev Biol, 2018. 76: p. 142-153.

28. Naranmandura, $\mathrm{H}$., et al., Mitochondria are the main target organelle for trivalent monomethylarsonous acid (MMA(III))-induced cytotoxicity. Chem Res Toxicol, 2011. 24(7): p. 1094103.

\section{Figures}



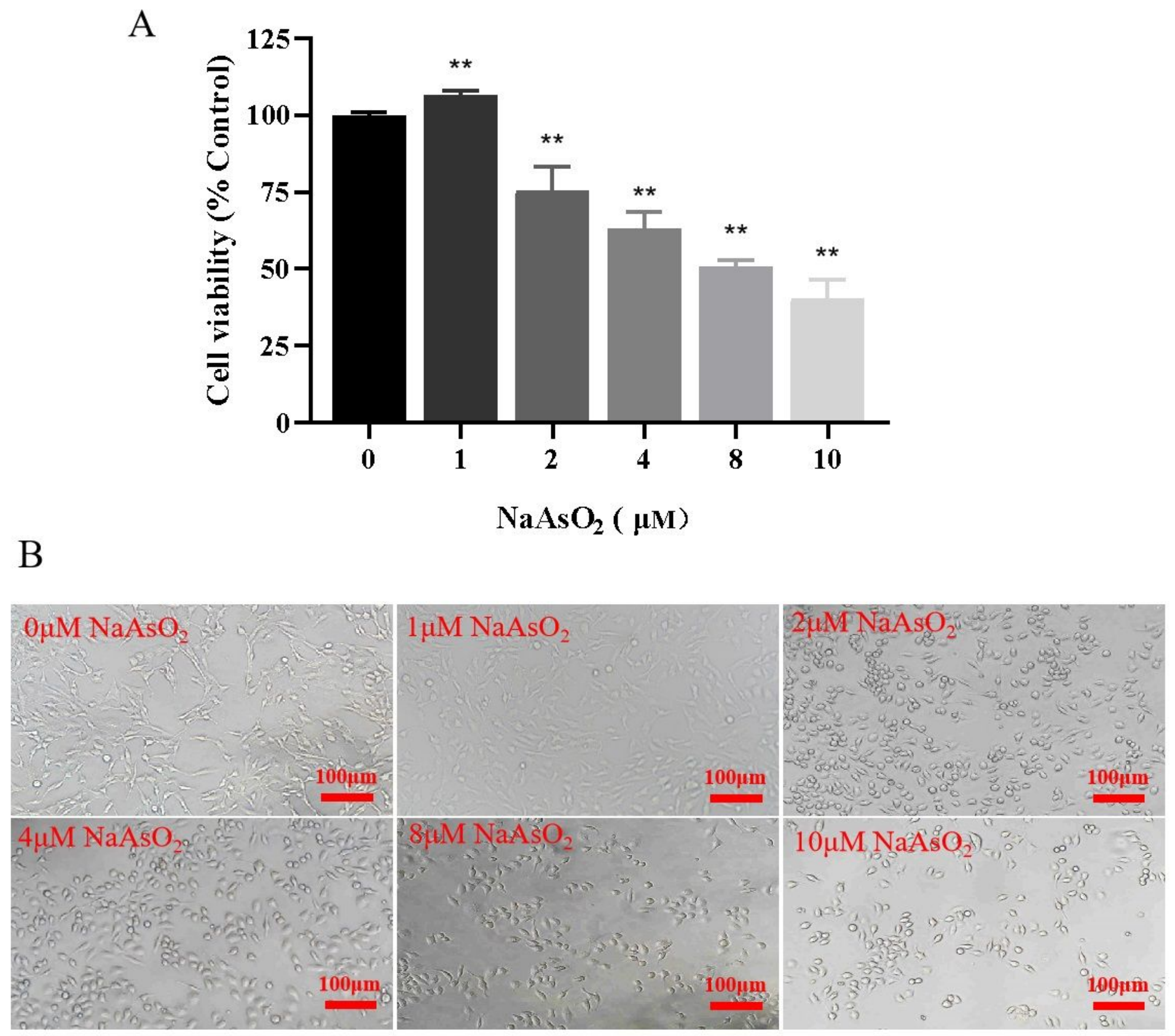

\section{Figure 1}

Vability changes of Beas-2B cells induced by NaAsO2. Beas-2B cells were cultured in $\mathrm{NaAsO} 2(0,1,2,4,8$ and $10 \mu \mathrm{M})$. (A) the cell viability was detected by CCK-8 kit. (B) Morphological changes of cells observed by inverted microscope. The experiment was repeated three times independently and all data were expressed as mean \pm standard deviation. ${ }^{* *}$ represented the comparison between the treatment group and the control group $(P<0.01)$ 


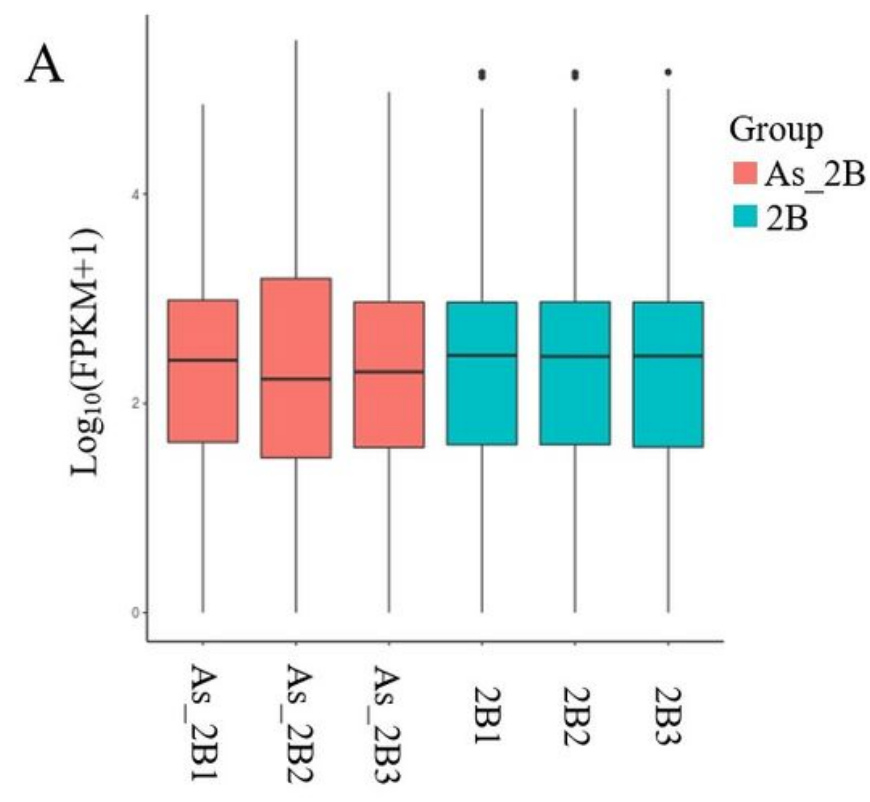

$\mathrm{B}$
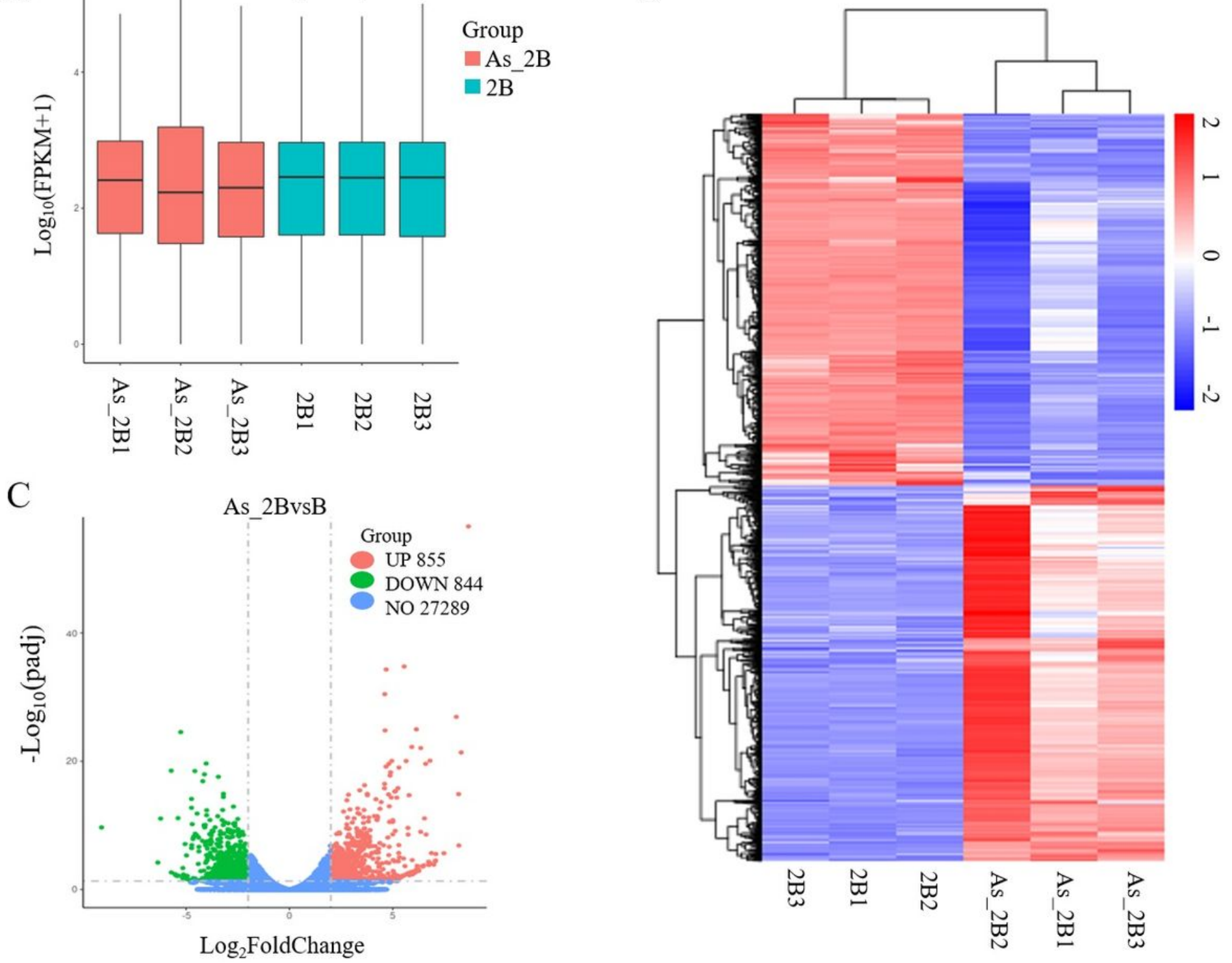

Figure 2

Evaluation of gene data quality and differentially expressed genes (DEG) of $\mathrm{NaAsO} 2$ treated cell samples. Beas-2B cells were exposed to $4 \mu \mathrm{M} \mathrm{NaAsO} 2$ for $24 \mathrm{~h}$ and then analyzed by RNA-seq sequencing. (A) The box diagram was used to compare the gene expression levels before and after $\mathrm{NaAsO} 2$ treatment. The abscissa represented cells groups under different treatment: As-2B 1, 2 and 3 represented the data of three independent tests of s-Beas-2B cells respectively, and 2B 1,2 and 3 were the data of three independent tests of Beas-2B cells. The ordinate represented Log10 (Fragments Per Kilobase of exon model per Million mapped fragments+1, FPKM+1). The box represented different intensities of gene expression from top to bottom: the highest point of the upper line was the maximum value, the upper end line was the upper quartile, the middle horizontal line was the median, the lower end line was the lower quartile, and the lowest point of the lower line was the minimum value of gene expression levels. (B) Cluster analysis of differently expressed genes between $\mathrm{NaAsO} 2$ treated cell and samples of the control groups. Genes or samples with similar expression patterns in the heat map would be gathered together, 
which could comprehensively and intuitively show the relationship and differences between each sample. Each grid reflected the value obtained after homogenization of the raw of expression data (generally between -2 and 2), so the colors in the heat map could only be compared horizontally (the expression of the same gene in different samples). Red color in the map represented the gene set with high expression and blue color represented the gene set with low expression. The left line represented the clustering of different genes, and the top line represented the clustering of samples with similar expression patterns. (C) Volcanic map of co-expressed genes between As-Beas-2B and Beas-2B cells. Differential genes were screened based on the criteria of $\mid \log 2$ (FoldChange) $\mid>1$ and $\operatorname{Padj}<0.05$.

A
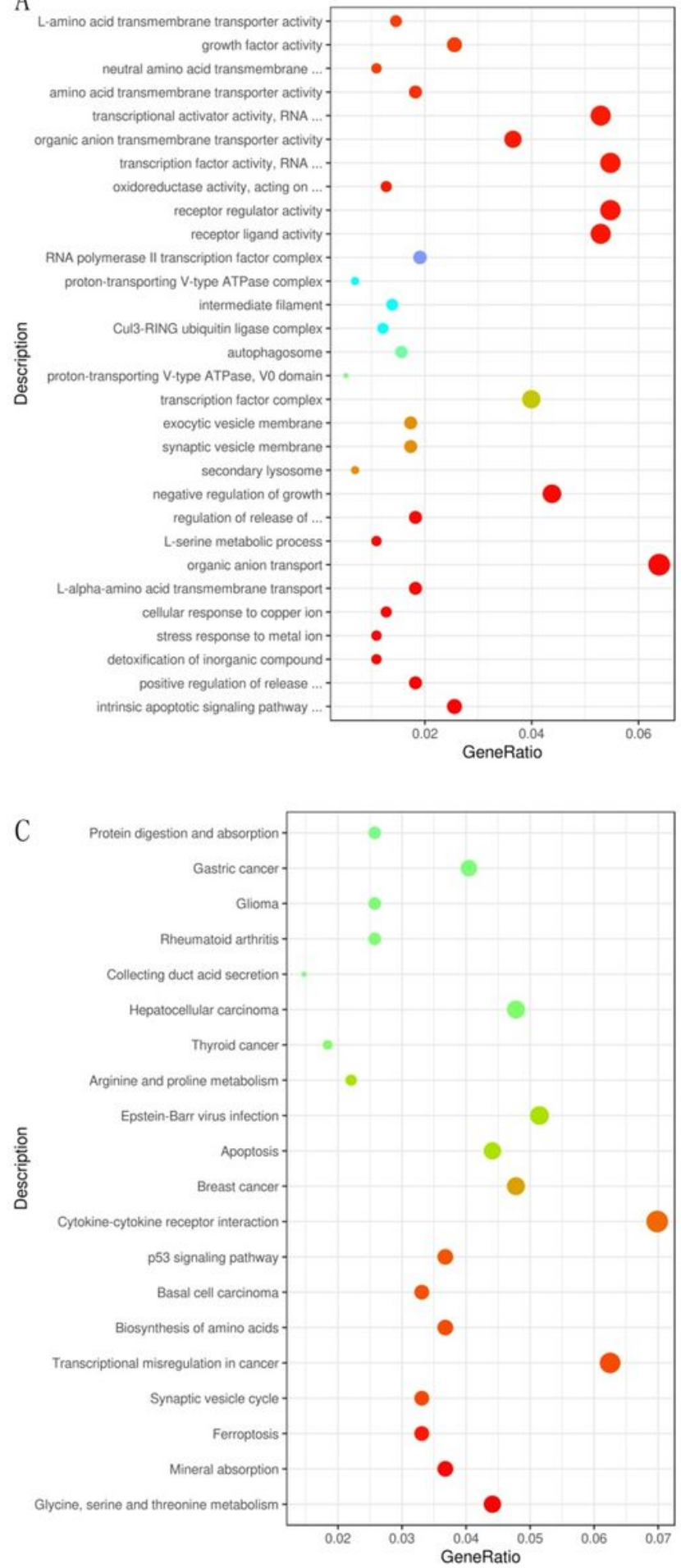

B

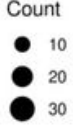

padj 1.00 을
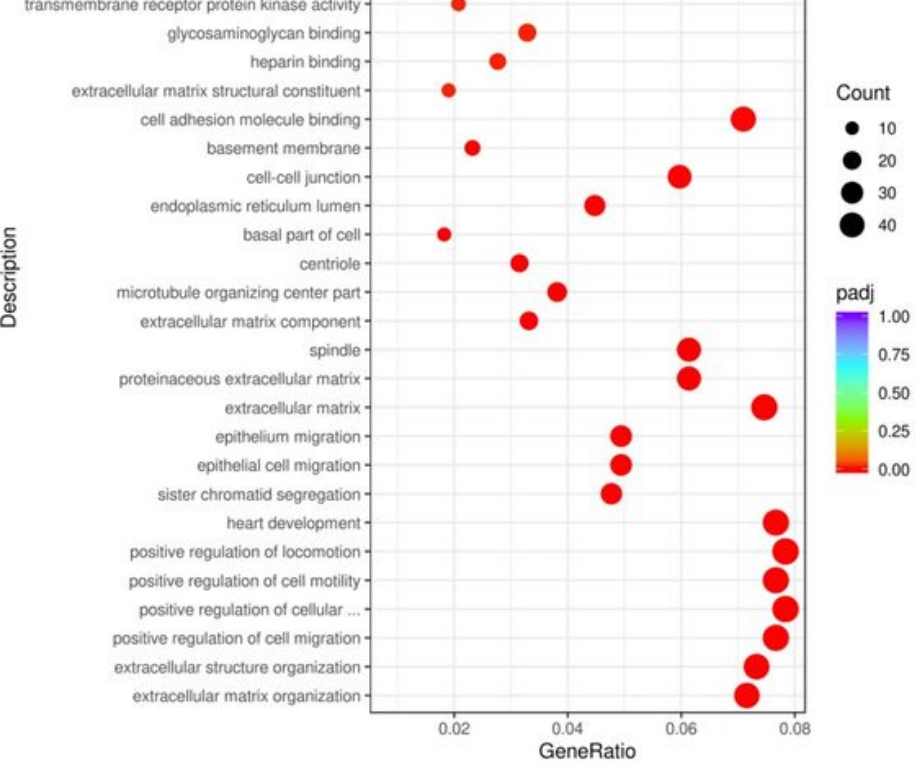

D

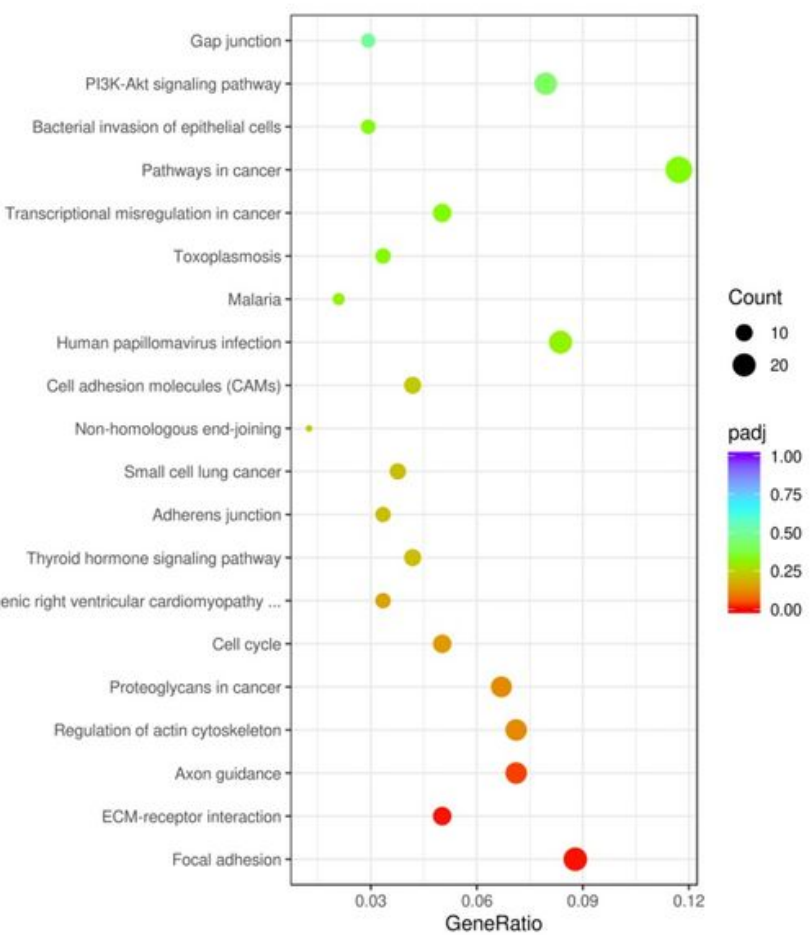




\section{Figure 3}

Gene profile changes induced by $\mathrm{NaAsO} 2$ exposure. (A\&B) The DEGs were analyzed by GO function enrichment analysis. The dot size in the figure indicated the number of genes enriched in this pathway and the depth of the red color represented the significant intensity of enrichments. (C\&D) The DEGs were analyzed by KEGG enriched pathway analysis.

A

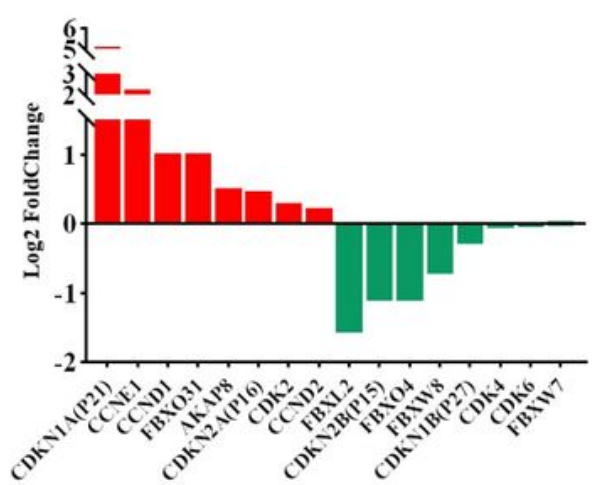

$\mathrm{C}$

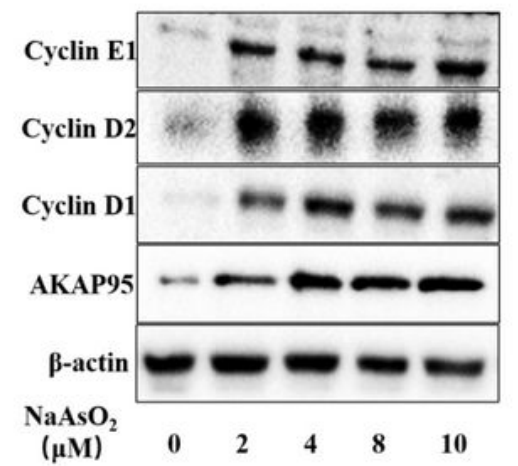

E

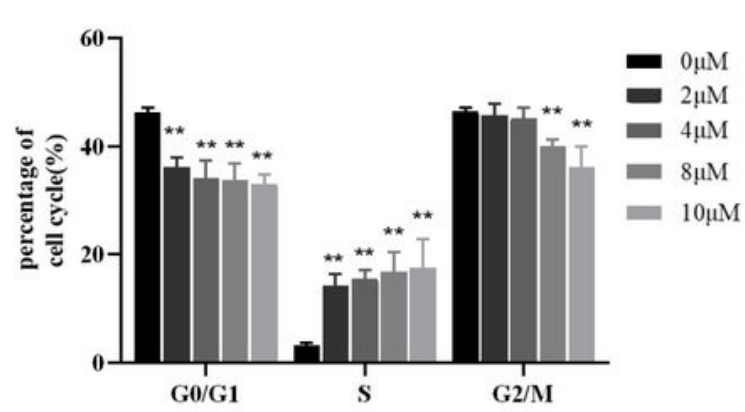

G

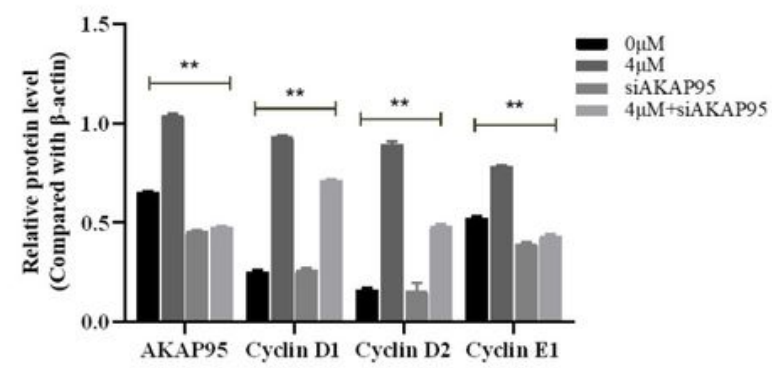

B

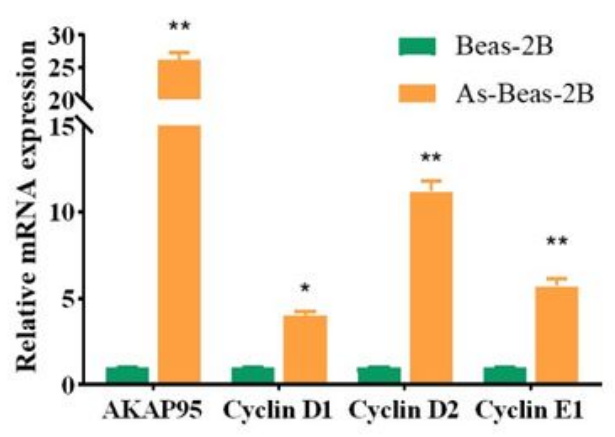

$\mathrm{D}$

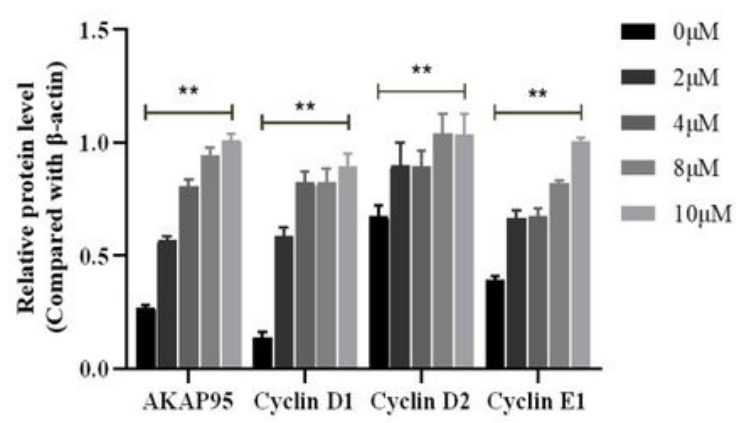

F

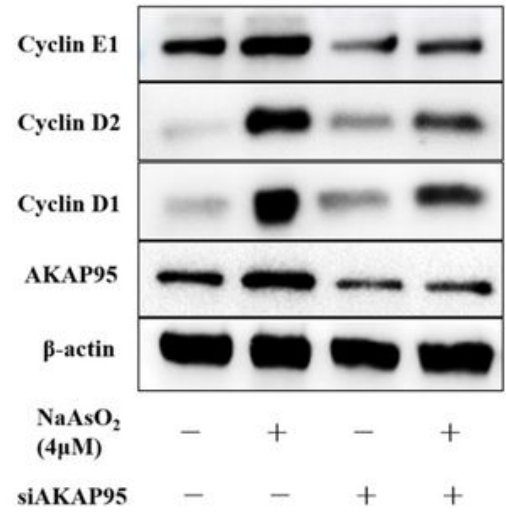

$\mathrm{H}$

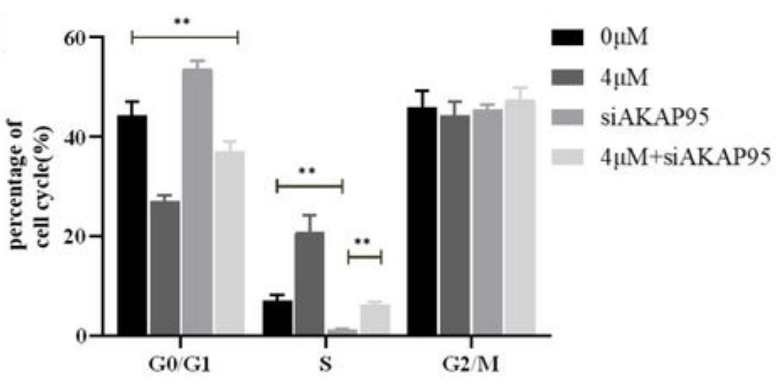

Figure 4 
Cell cycle changes caused by $\mathrm{NaAsO} 2$. (A)Beas-2B cells were cultured and exposed in $4 \mu \mathrm{M} \mathrm{NaAsO} 2$ for 24 hours, and RNA-Seq assay was used to screen the differential genes in the cell cycle transition pathway of cells before and after $\mathrm{NaAsO} 2$ exposure. (B) qRT-PCR assay was used to verify gene expression results of RNA-Seq. (C) After exposure in 0, 2, 4, 8 and $10 \mu \mathrm{M} \mathrm{NaAsO} 2$ for 24 hours, WB assay was used to detect expressions of AKAP95, cyclin D1, cyclin D2 and cyclin E1. The antibodies were diluted at 1:1000. (D) Statistical results of C. Data were expressed as mean \pm standard deviation $(n=3)$, and nonparametric t-test was used for statistical analysis. (E) Effects of 24h- different $\mathrm{NaAsO} 2$ concentrations treatment on cell cycle progression were measured by flow cytometry. (F\&G) WB assay was used to detected expressions of cyclins in AKAP95 silenced Beas-2B cells after $24 \mathrm{~h}-4 \mu \mathrm{M} \mathrm{NaAsO} 2$ treatment. $(\mathrm{H})$ Flow cytometry was used to analyze changes of proportion of silence Beas-2B cells in each phase of cell cycle, after $24 \mathrm{~h}-4 \mu \mathrm{M} \mathrm{NaAsO} 2$ treatment. All data were analyzed by Analysis of variance (ANOVA) and Pairwise Comparison of the Mean of multiple samples and expressed as mean \pm standard deviation $(\mathrm{n}=3)$. * represented $\mathrm{P}<0.05$ and ** represented $\mathrm{P}<0.01$. 

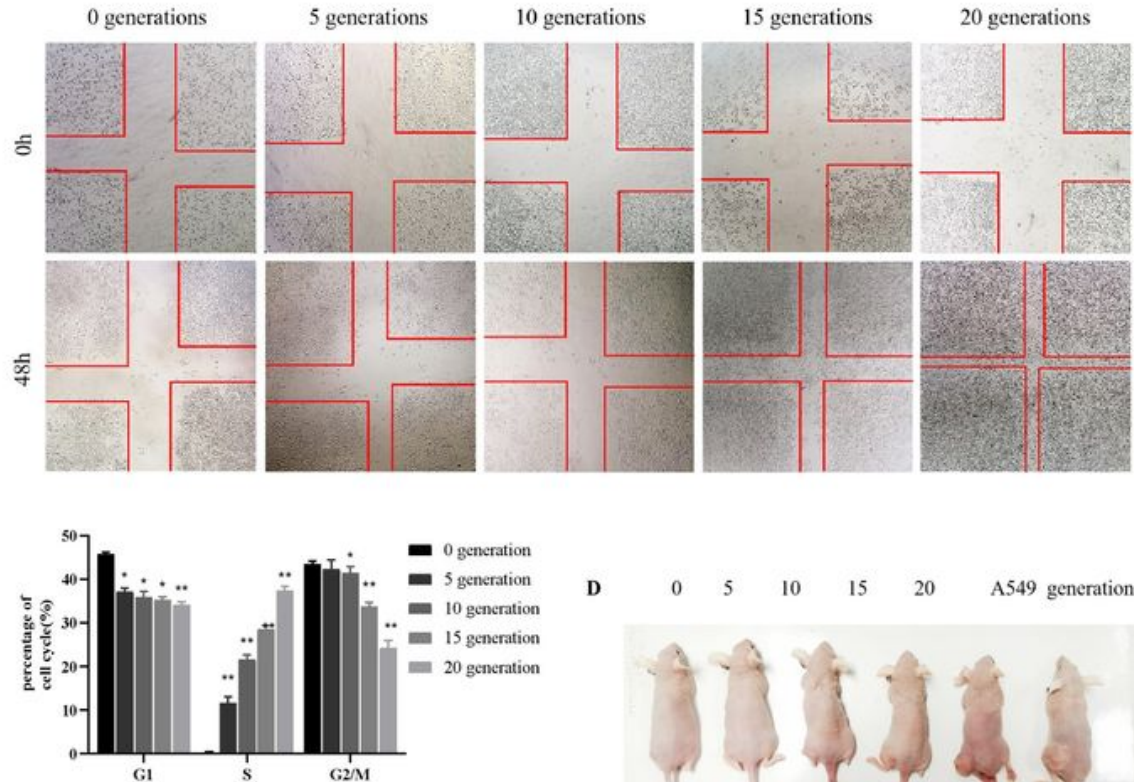

C

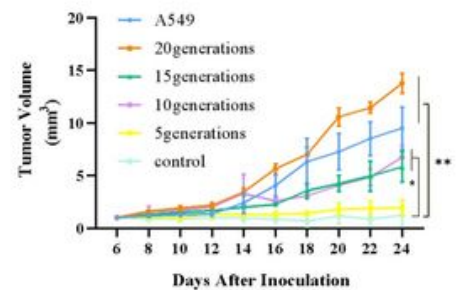

$\begin{array}{lllllll}\text { D } & 0 & 5 & 10 & 15 & 20 & \text { A549 generations }\end{array}$

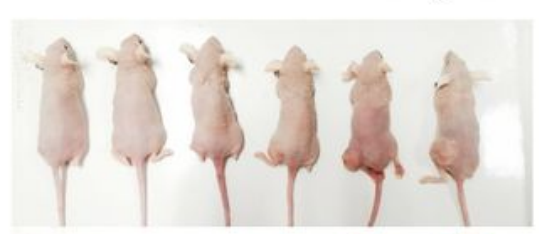

E

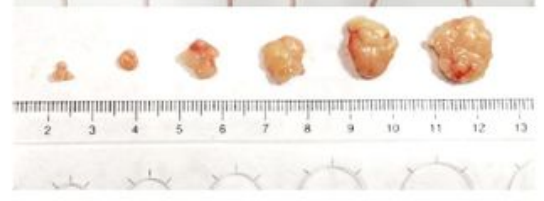

Days After Inoculation

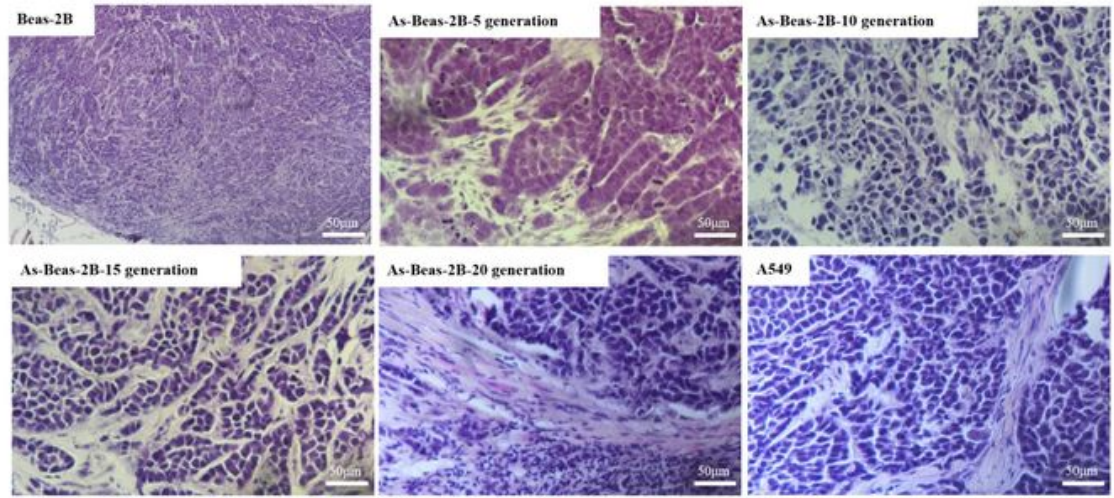

G

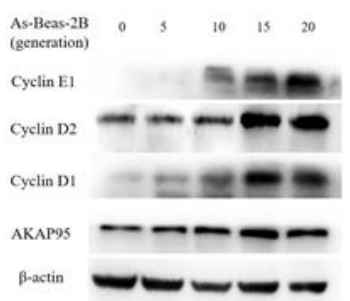

Figure 5

Tumor bearing experiment of BALB/C female mice. (A) Beas-2B cells were continuously exposed to $1 \mu \mathrm{M}$ $\mathrm{NaAsO} 2$ and sub cultured for 20 generations. $48 \mathrm{~h}$ scratch test was used to analyze the changes of cell proliferation and migration rate of exposed cells. (B) Beas-2B cells were continuously exposed to $1 \mu \mathrm{M}$ $\mathrm{NaAsO} 2$ and sub cultured for 20 generations. Proportions of cells in different stage were detected by flow cytometry, and all data were expressed as mean \pm standard deviation $(n=3)$ and analyzed by 
nonparametric t-test, compared with the control group. * represented $\mathrm{P}<0.05$ and $* *$ represented $\mathrm{P}<0.01$. (C) Different generations As-Beas-2B cells that continuous exposed to $1 \mu \mathrm{M} \mathrm{NaAsO2}$ were inoculated into the left hindlimb of mice at the same time, and the growth curve of tumor volume growth for 24 days was continuously monitored. (D\&E) Photographs of bear tumor tissues removed form mice after 24 days of As-Beas-2B cells injection. (F) Images of HE stanning of fixed tumor tissues. (G) Expressions of AKAP95, cyclin D1, cyclin D2 and cyclin E1 in tumor tissues.
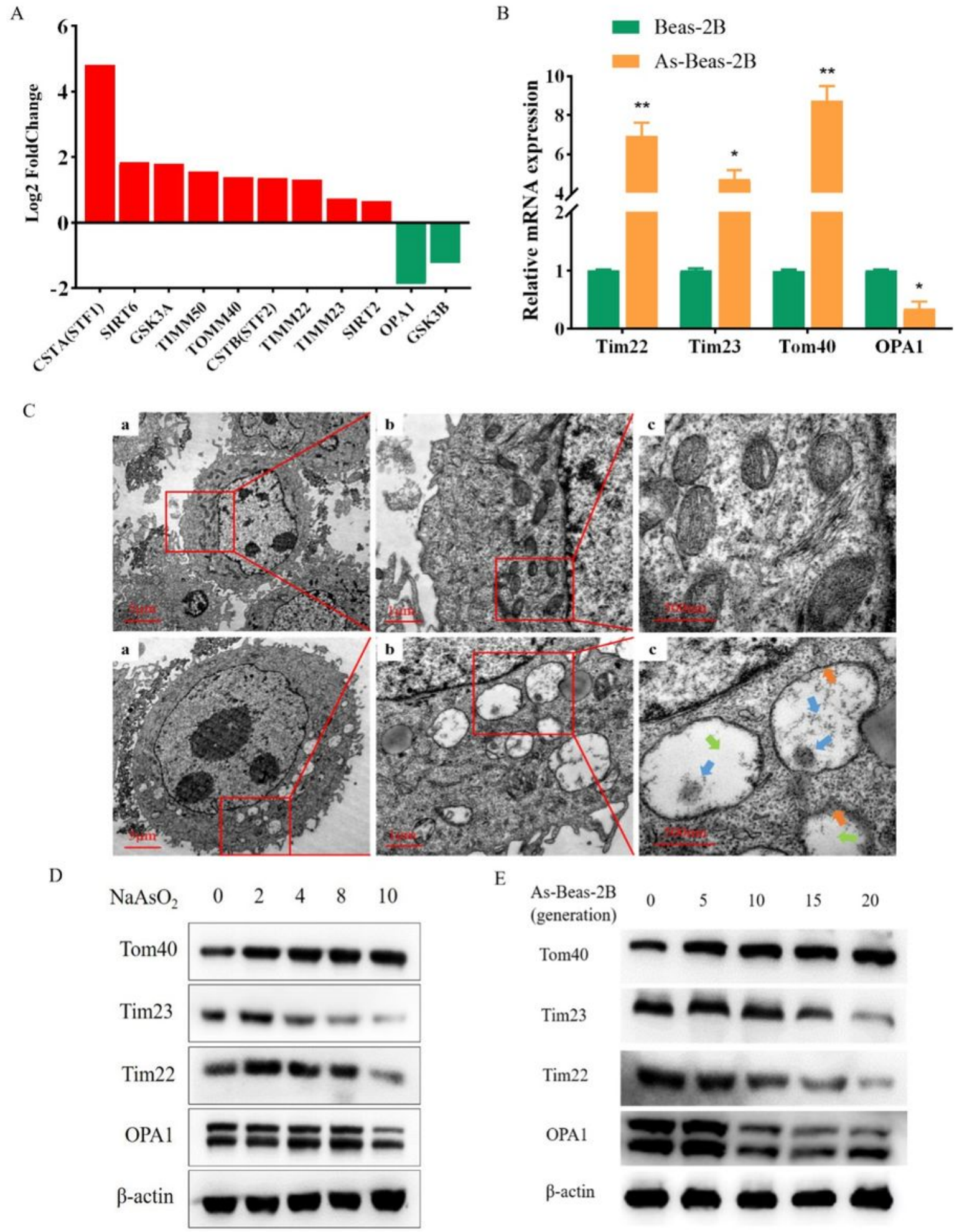

Figure 6 
Morphological changes caused by $\mathrm{NaAsO} 2$ damages to cell mitochondria. (A) Beas-2B cells were cultured in $\mathrm{NaAsO} 2(0,2,4,8$ and $10 \mu \mathrm{M})$ for 24h, and the differential genes in the pathway of mitochondrial damage before and after $\mathrm{NaAsO} 2$ exposure were screened by RNA-seq assay. (B) Changes of some mitochondrial function related genes in RNA-seq results were verified by qRT-PCR assay. (C) TEM assay was used to detect morphological changes of Beas-2B cells treated with $4 \mu \mathrm{M} \mathrm{NaAsO} 2$ for $24 \mathrm{~h}$.

The upper picture showed cells in the control group and the lower picture showed the cells in the $\mathrm{NaAsO} 2$ exposure group. The magnification increased gradually from the left to the right picture (e.g.: Figure. $6 \mathrm{Cb}$ was an enlarged picture of $6 \mathrm{Ca}$ ). The yellow arrow pointed to changes of double membrane structure, the blue arrow pointed to the wrinkled mitochondrial ridge, and the green arrow pointed to the increased mitochondrial vacuole. (D) WB assay was used to detect expression changes of Tim22ロTim23ロTom40 and OPA 1 in cells treated with different concentrations of $\mathrm{NaAsO2}$. Dilution ratio of all antibodies was 1:1000. (E) After continuous exposure to low dose $1 \mu \mathrm{M} \mathrm{NaAsO2}$, As-Beas-2B cells of different generations were inoculated subcutaneously into mice. After 24 days of tumor growth, the bare tumor tissues were taken out and detected the expression of mitochondrial function related proteins Tim22, Tim23, Tom40 and OPA1. 
A
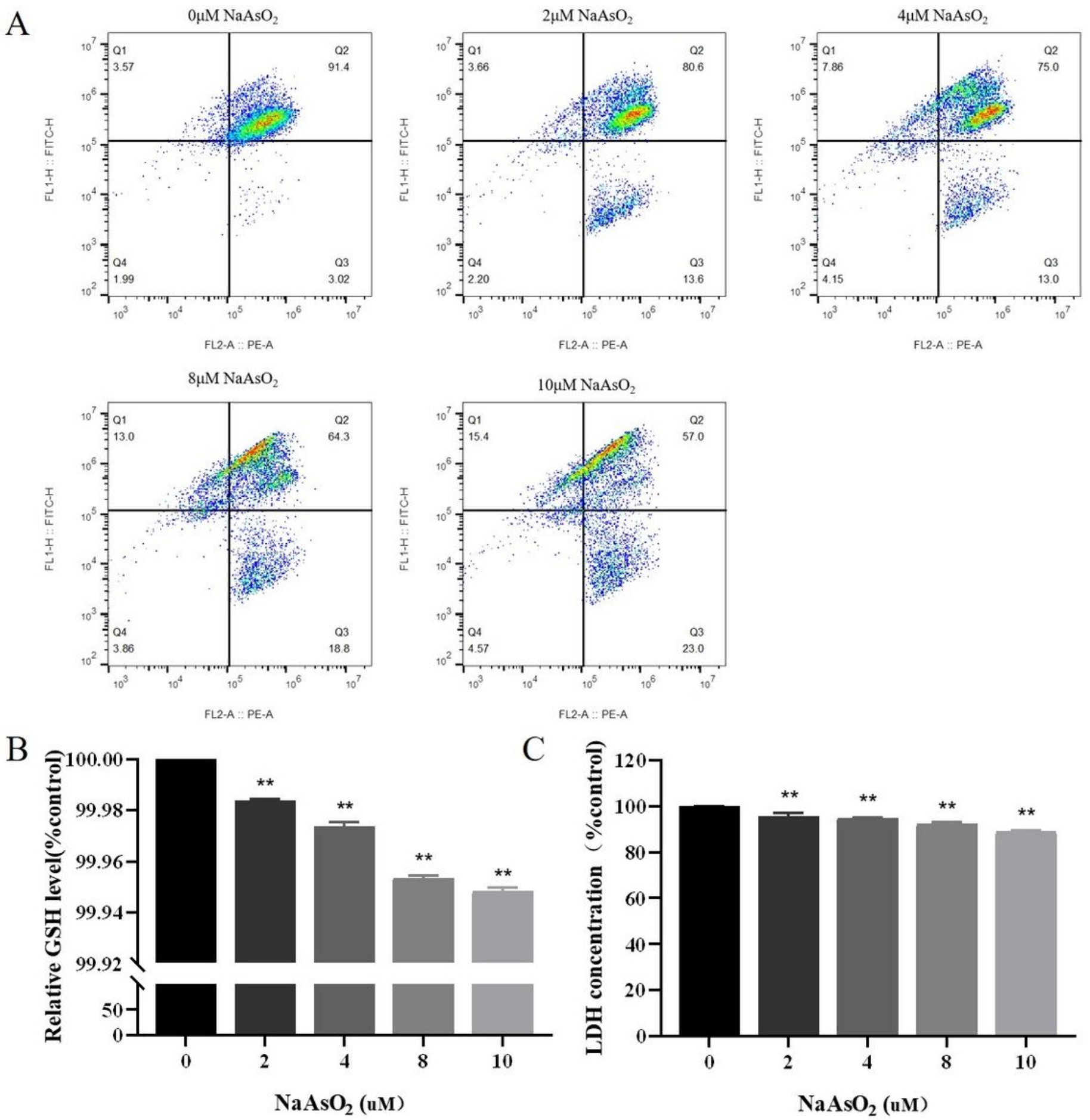

$F L 2-A=P E-A$

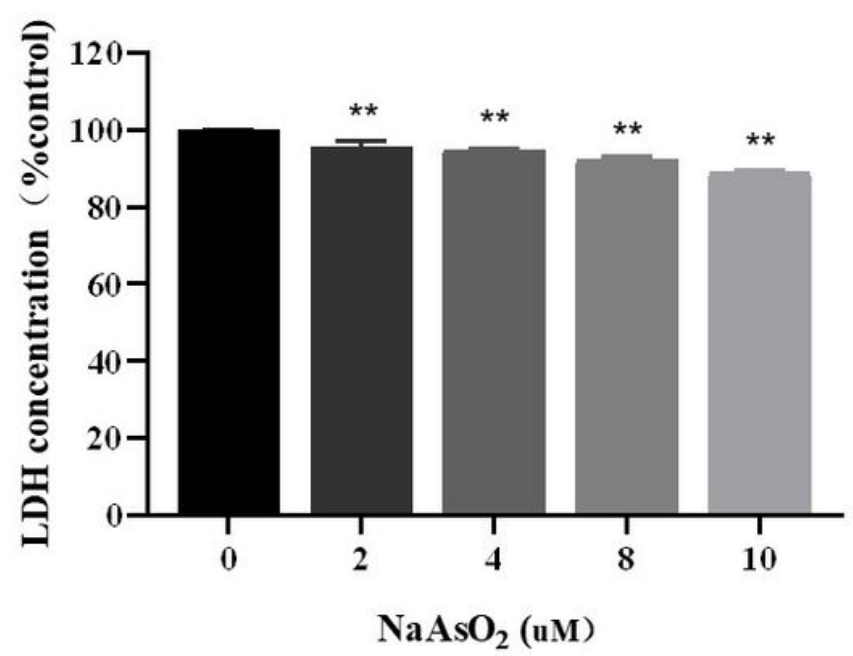

Figure 7

Mitochondrial function damage induced by NaAsO2. (A) Beas-2B cells were exposed to $\mathrm{NaAsO} 2(0,2,4,8$ and $10 \mu \mathrm{M})$ for $24 \mathrm{~h}$, and the mitochondrial membrane potential of collected cells was detected by JC-1 fluorescent probe. (B\&C) By standardizing GSH and LDH contents to the protein content in a certain number of cells, relative levels of GSH and LDH content in cell lysates before and after $\mathrm{NaAsO} 2$ exposure were detected and compared. All data were expressed as mean \pm standard deviation $(n=3)$. Statistical 
analysis was performed by nonparametric t-test, and ** represented the comparison between treatment and control group, $\mathrm{P}<0.01$. 